\title{
Bangladesh Perspective: Vehicle Speed Proposition System Using Localized Wireless Identification
}

\author{
Mehdi Hasan Chowdhury, Md. Mamunoor Islam \\ Department of Electrical and Electronic Engineering, Chittagong University of Engineering \& Technology, Bangladesh
}

\begin{tabular}{l}
\hline \hline Article Info \\
\hline Article history: \\
Received Apr 22, 2016 \\
Revised Jul 14, 2016 \\
Accepted Aug 2, 2016 \\
\hline
\end{tabular}

\section{Keyword:}

Road Accident

Speed Limit

RF Communication

RF Transmitter

RF Receiver

\begin{abstract}
Even in the era of advanced engineering, road accident has been a regular phenomenon causing death of many people in Bangladesh due to over speeding action of reckless drivers. There are several key places (such as schools, colleges, hospitals, highways and constructional areas etc.) where the speed of the vehicle should be lessened to avoid accidents. The roads and highways authority may place the speed limiter signboards in these areas to avoid these accidents, but these are frequently overlooked by the drivers. So this paper demonstrates a wireless forewarning system which will aid to control the speed of the vehicles at speed restricted areas. The whole system is established on the basis of radio frequency (RF) communication. There are two parts of this system named as transmitting unit and receiving unit. Each RF transmitter positioned on the roadside will be transmitting the code signal continuously. Whenever the vehicle enters the range of transmission, the RF receiver which is attached in the vehicle, will receive the signal and will display the information in a LCD monitor by notifying the driver to reduce the speed while going through that area.
\end{abstract}

Copyright (C) 2016 Institute of Advanced Engineering and Science. All rights reserved.

\section{Corresponding Author:}

Md. Mamunoor Islam,

Department of Electrical and Electronic Engineering,

Chittagong University of Engineering \& Technology,

Chittagong-4349, Bangladesh.

Email: mcm.mithu@gmail.com

\section{INTRODUCTION}

It is apparent that road accidents have turned out to be a topmost menace in this emerging world. With the rapid growth of technology and infrastructure, human life has become easier. But the advent of technology has also increased the traffic hazards and the road accident which causes huge loss of life and property [1]. Every year the lives of almost 1.24 million people are cut short as a result of road accidents [2]. About 20 to 50 million more people suffer nonfatal injuries, with many incurring a disability as a result of their injury. Without action, road traffic crashes are predicted to result in the deaths of around 1.9 million people annually by 2020.

The World Health Organization (WHO) also projects that road crash injuries will be the third highest threat to public health by 2020 [2]. As a developing country in the world, the increase of road deaths has been an alarming concern of Bangladesh. According to police report total number of road traffic accidents was 40,927 in Bangladesh during period of 2001-2010, and number of killed person was 32,261. In 2010; 3,300 people were killed in road accidents, which rose to 5928 in 2011, a rise of $80 \%$. Moreover, the estimated cost of these road accidents is approximately $7500 \mathrm{Cr}$ Bangladeshi taka (1 USD=80 BDT) per year. This is said to be $1.5 \%$ of GDP which directly effects in the national economy [3].

According to the road safety status reports by WHO shown in Figure 1, it is clear that the pedestrians (41\%) are mostly affected in traffic speed limit and hasty actions of drivers. Recent studies show that one third of the number of fatal or serious accidents are associated with excessive or inappropriate speed 
in the speed restricted areas [4]. So reduction of the number of accidents and alleviation of their consequences are an enormous concern for roads and highways department [5]. For the remedying, deterrent speed restraint signboards are placed in dicey area where the probability of accident incidence is enormous. However, most of the times these signboards go unnoticed by the drivers because it's not easy to keep an eye out while driving. So many innocent pedestrians experience deaths because of the over speeding action of drivers. Being a developing county, different latest technologies such as Google maps etc. are not so available for drivers in Bangladesh.

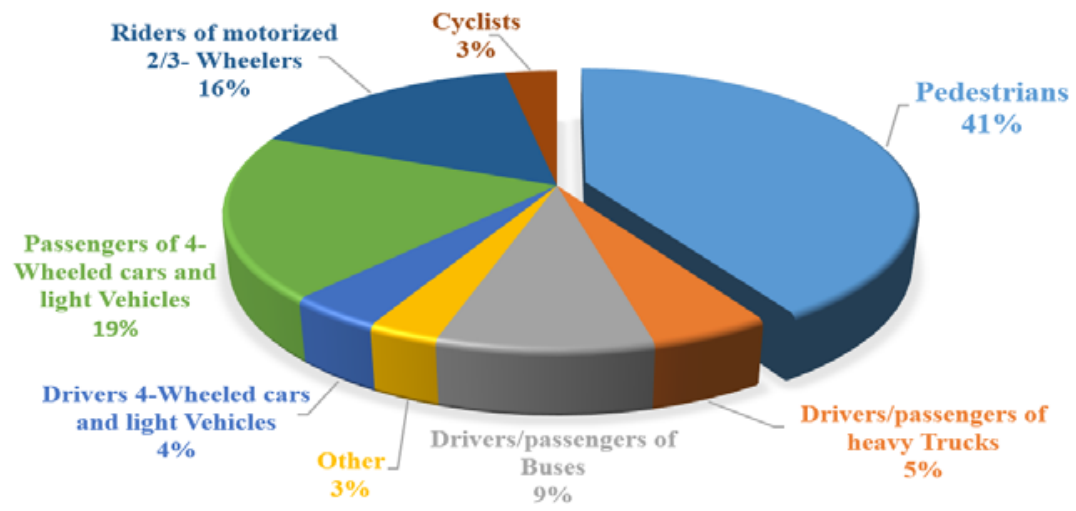

Figure 1. Deaths by road users’ category in Bangladesh [6]

Different driving assistance systems have been developed to avoid these road accidents. An intelligent vehicle control system based on identification of road and traffic signal has been developed by A. K. Thirukkovulur et al. [7] to alert the drivers which is Operated by RFID transponders. But the system has the limitation of range between transmitter and receiver which is the drawback for high speedy vehicle. Another over speed violation management system of a vehicle through ZIGBEE communication has been established in 2013 (Rubini et al.) which is not cost effective [8]. An architectural design of the vehicle tracking system based on RFID has been proposed by Jianxin Deng in 2013 [9] and an approach for testing of radio frequency identification and parameter analysis has been proposed by Lidong Wang in 2014 [10].

Hence this paper represents an assistance system based on radio frequency communication for the drivers which will notify them about the speed restriction in the hazardous areas wirelessly. So they will be cautious in advance while crossing that area which results in decline of accidents. This system has been implemented practically both for slow and high speed vehicles and it has no significant range limitation (approximately 200 meters transmission range) with provision of cost effectiveness.

\section{RESEARCH METHOD}

The proposed system is established on Radio frequency communication. A radio frequency (RF) signal refers to a wireless electromagnetic signal which is formed from electromagnetic radiation with identified radio frequencies [11]. In this work, an ISM band frequency (434 MHz) has been used as transmitting frequency. In RF communication, there must be two units such as RF transmitter and RF receiver. In the risky area, speed should be less than other zones for avoiding the accidents. For example, in front of schools and hospitals the speed of the vehicles should not cross $30 \mathrm{~km} / \mathrm{h}$.

So in this assistance system, RF transmitters are placed in the speed restraint signboards which will transmit the information of speed limit continually, as shown in Figure 2. The RF receiver is equipped in the vehicle, which receives the signal when the vehicle enters into the transmission region. Then it aids the driver by apprising him about the speed bounds of that particular area. In this time, the driver will lower the speed of his vehicle conferring to that information.

As earlier decribed, there are two parts such as transmitting and receiving units in the projected system. In the transmitting circuit, RF encoder IC (HT12E) has been used for converting the input parallel data to serial data. There are 8 address pins in the encoder IC which can be used to set a particular address for the receiver to which the data have been transmitted. 


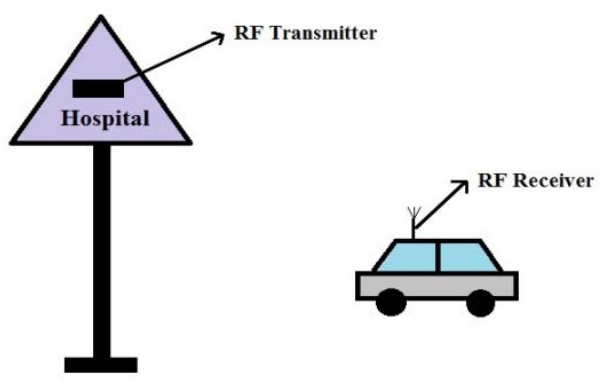

Figure 2. Traffic Signboards equipped with RF transmitter (left side) Vehicle equipped with the RF receiver (right side) [12]

There are also four input pins $\left(\mathrm{Q}_{1}, \mathrm{Q}_{2}, \mathrm{Q}_{3}, \mathrm{Q}_{4}\right)$ in RF encoder IC by which ( $\left.2^{4}=16\right)$ combinations of 4 bits binary data can be sent, as shown in Table 1 and Figure 3. These input bits are transmitted by the RF transmitter which transmits the signal at the frequency of $434 \mathrm{MHZ}$. In the experimental system various combinations of input bits are tested for some areas.

Table 1. Test Combinations

\begin{tabular}{lcccc}
\hline \multicolumn{1}{c}{ Area } & $\mathrm{Q}_{1}$ & $\mathrm{Q}_{2}$ & $\mathrm{Q}_{3}$ & $\mathrm{Q}_{4}$ \\
\hline School Area & 1 & 0 & 0 & 0 \\
Hospital Area & 0 & 1 & 0 & 0 \\
Constructional Area & 1 & 1 & 0 & 0 \\
Hill Area & 0 & 0 & 1 & 0 \\
\hline
\end{tabular}

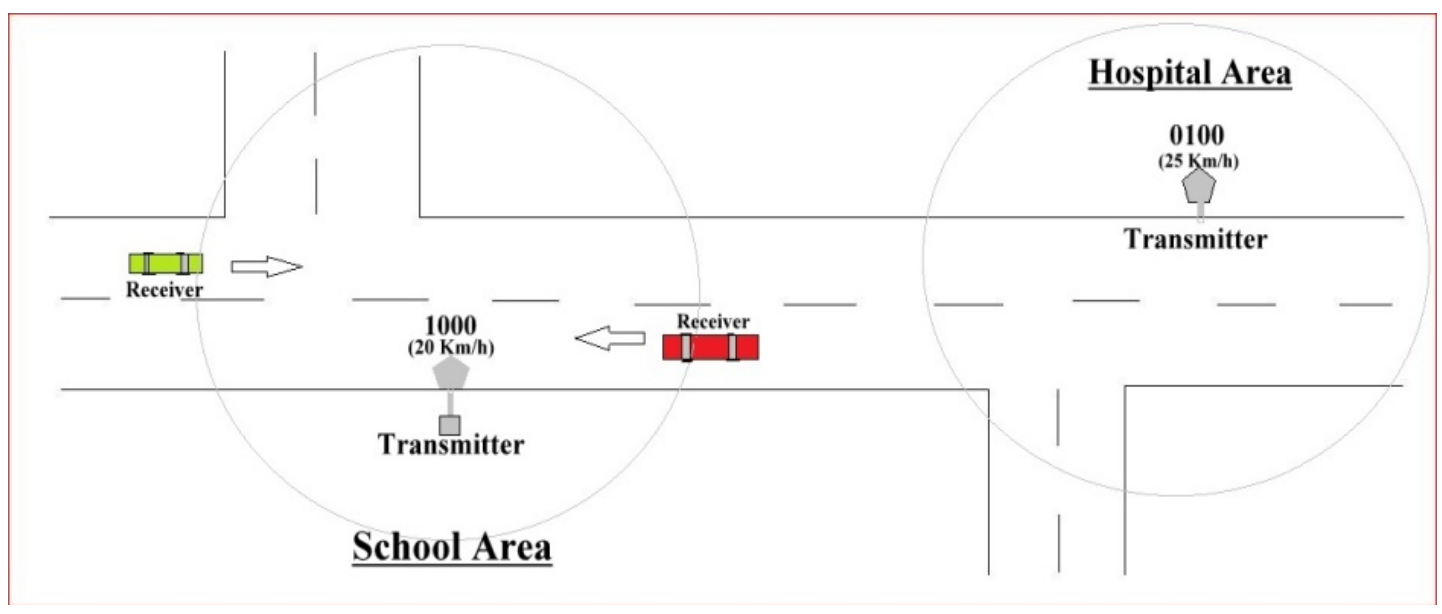

Figure 3. Real life network model

As Figure 3, the input bits are transmitted by the RF transmitter through its antenna. As the transmitting frequency is high, the antenna length is an important factor for effective transmission. The length of the antenna should be $17.25 \mathrm{~cm}$ both in transmitting and receiving side as the transmission frequency is $434 \mathrm{MHZ}$. The receiving side must have the same address set by the transmitting side. So in this system, multiple vehicles can receive the same information at a time but there must be the same address in every receiving device. 


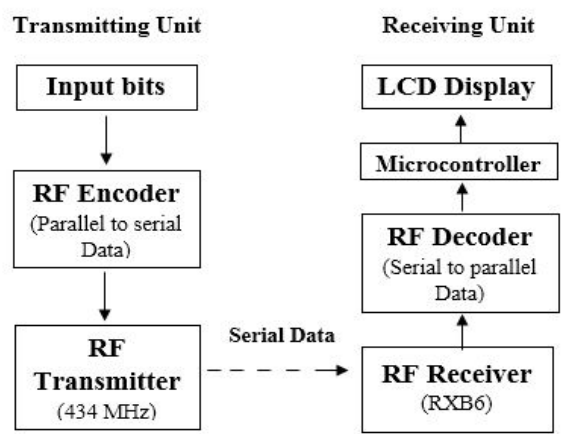

Figure 4. Basic operational method

The input bits are received by RF receiver module (RXB6). These serial data are conveyed to the RF decoder IC (HT12D) to convert these into parallel data. The outputs of decoder IC is directly sent to the microcontroller. Then microcontroller will display the information to the LCD monitor, as shown in Figure 4. Figure 5 shows the diagram of necessary circuit used in transmitting device and Figure 6 demonstrations circuits of receiving devices.

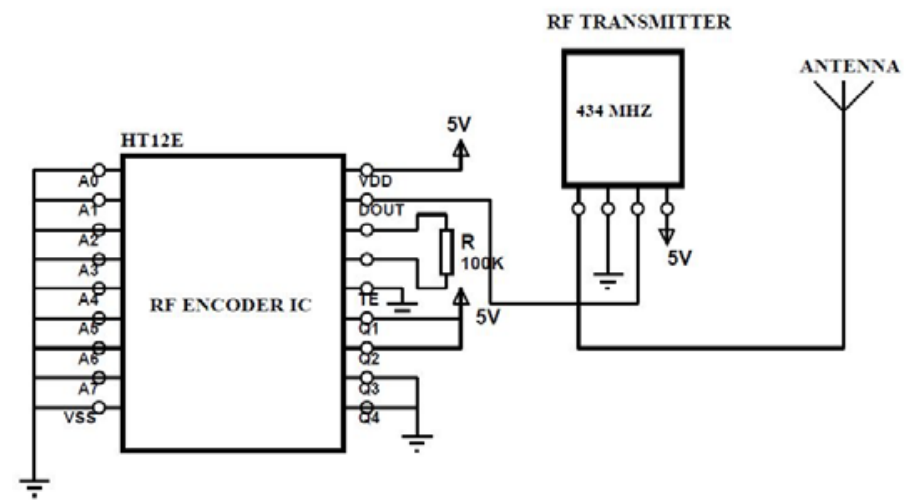

Figure 5. Circuit diagram of transmitting device

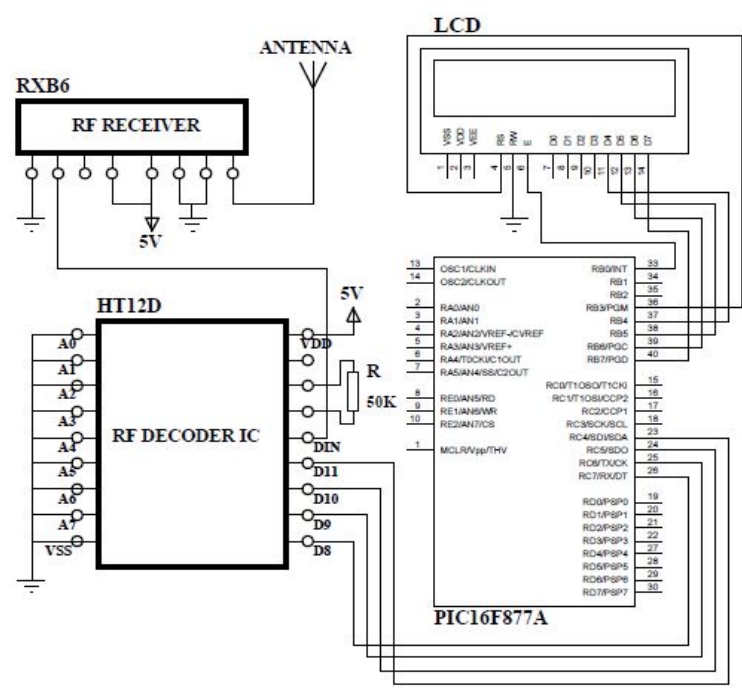

Figure 6. Circuit diagram of receiving device 


\section{RESULTS AND ANALYSIS}

The system has been practically implemented in some of the vehicles for testing the response of the system. Relevant data have been collected from practical setup to find out speed vs. transmission distance relationship which is illustrated in Figure 7.

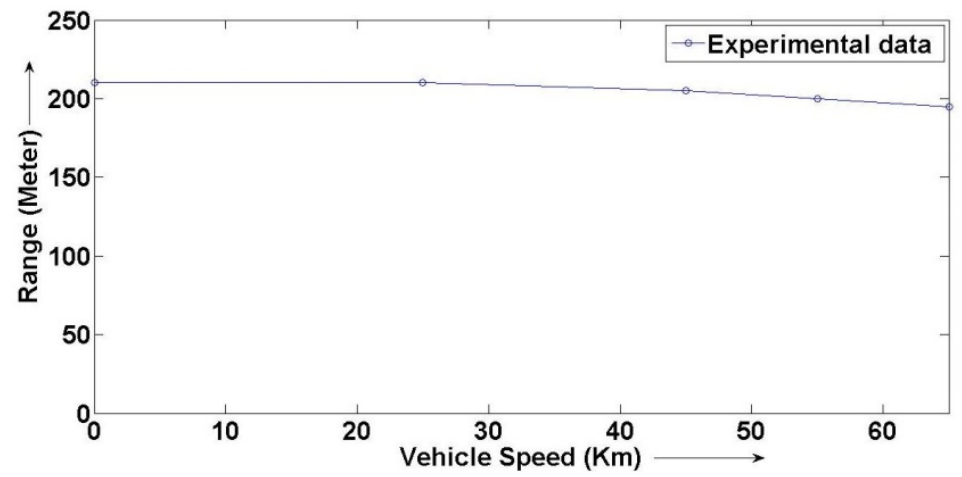

Figure 7. Speed vs. Transmission range graph

It is evident from the Figure 7 that the transmission range of the system is hardly affected by the speed factor of the vehicle. Though there is a slight decrease in the range when the vehicle is at high speed. But this decrease is pretty negligible. So it can be said that the system performs well both for slow and speedy vehicles which should be an imperative criteria for practical application.

For the wide-spread implementation of this system, let's take Dhaka city as an example. From the data table (Table 2 and Table 3), it is noticed that the power consumption of both transmitting and receiving device is quite low. Hence large scale implementation of this system is feasible. If there is 100 transmitting devices placed in different zones and for example, 10000 vehicles will be equipped with the receiving device then total power consumption of both devices for one day is shown in Table 3 and Table 4.

Table 2. Power Consumption for Transmitting Device

\begin{tabular}{lc}
\hline \multicolumn{1}{c}{ Parameters } & Transmitting Device \\
\hline Supply voltage (Volt) & $5 \mathrm{~V}$ \\
Power per device (Watt) & $0.03 \mathrm{~W}$ \\
Power For 100 Transmitters (Watt) & $3 \mathrm{~W}$ \\
Electricity units for one day (Kw-h) & 0.072 \\
(Unit= $\mathrm{W}^{*}$ thour /1000) & 0.07 \\
\hline
\end{tabular}

Table 3. Power Consumption for Receiving Device

\begin{tabular}{lc}
\hline \multicolumn{1}{c}{ Parameters } & Receiving Device \\
\hline Supply voltage (Volt) & $4.85 \mathrm{~V}$ \\
Power per device (Watt) & $0.193 \mathrm{~W}$ \\
Power For 10000 Receiviers (Watt) & $1930 \mathrm{~W}$ \\
\hline
\end{tabular}

In a comparative study between the proposed assistance system and existing systems (Table 4), it is apparent that the proposed system has the least cost of all. Though the transmission range is less than the ZIGBEE based system, the range of the proposed system is practically enough for a driver to control the speed of his vehicle.

Table 4. Comparative Study

\begin{tabular}{lcc}
\hline \multicolumn{1}{c}{ Name of the System } & $\begin{array}{c}\text { Effective Range } \\
\text { (Meters) }\end{array}$ & $\begin{array}{c}\text { Cost (Approximate) per receiver In BDT } \\
\text { Taka (1\$=80 taka) }\end{array}$ \\
\hline The proposed system & 210 & 600 \\
RFID based system [7] & 50 & 1000 \\
Zigbee based system [8] & 1000 & 3000 \\
\hline
\end{tabular}




\section{CONCLUSION}

In future, voice warning and GSM module may be added to this system by which drivers can be alerted with voice warning and if any driver doesn't reduce the speed according to the speed restriction, a message will be sent to the authority and proper steps can be taken against the driver for violating the speed limit. This research has been designed to decline the number of accidents and to alert the drivers about the speed limits for safe driving at the high accident zone. The overall cost and power consumption have been quite low of this system so that it's very easy to implement in the real life by which the driver will get necessary information about the road without any distraction which results in scaling down the number of hazardous road accidents.

\section{REFERENCES}

[1] V. Goud and V. Padmaja, "Vehicle Accident Automatic Detection and Remote Control Device," International Journal of Reconfigurable and Embedded Systems (IJRES), vol/issue: 1(2), pp. 49-54, 2012.

[2] Road Traffic Injuries: Fact sheet $\mathrm{N}^{\circ} 358$, www.who.int/mediacentre/factsheets/fs358/en/Roadtraffic injuries. Retrieved on April 2016.

[3] S. K. Biswas, "Road Traffic Injuries: an Emerging Problem in Bangladesh,” Faridpur Med. Coll. J., vol/issue: 7(1), pp. 05, 2012.

[4] A. Mishra, et al, "Design of RF based speed control system for Vehicles," International Journal of Advanced Research in Computer and Communication Engineering, vol/issue: 1(8), pp. 583-586, 2012.

[5] K. Govindaraju, et al, "Embedded Based Vehicle Speed Control System Using Wireless Technology," International Journal of Innovative Research in Electrical, Electronics, Instrumentation and Control Engineering, vol/issue: 2(8), 2014.

[6] Global status on road safety, 2013. Retrieved on April 2016 www.who.int/ violence_injury_prevention/road_safety_status/2013/country_profiles/bangladesh.pdf.

[7] A. K. Thirukkovulur, et al, "Intelligent Vehicle Control Based on Identification of Road and Traffic Signal Operated RFID transponders," Proceedings of International Conference on Advances in Electrical and Electronics Engineering (ICAEE'2012), Penang, Malaysia, 2012.

[8] R. Rubini and A. U. Makeswari, “Over Speed violation management of a vehicle through ZIGBEE,” International Journal of Engineering and Technology (IJET), vol/issue: 5(1), pp. 340-344, 2013.

[9] J. Deng, “Architecture Design of the Vehicle Tracking System based on RFID,” TELKOMNIKA, Indonesian Journal of Electrical Engineering, vol/issue: 11(6), pp. 2997 -3004, 2013.

[10] L. Wang, “Testing of Radio Frequency Identification and Parameter Analysis Based on DOE,” International Journal of Electrical and Computer Engineering (IJECE), vol/issue: 4(1), pp. 145-150, 2014.

[11] C. Coleman, “An Introduction to Radio Frequency Engineering,” Cambridge University Press, July 2011.

[12] G. Sattibabu, et al., "Automatic Vehicle Speed Control with Wireless in-Vehicle Road Sign Delivery System Using ARM 7,” International Journal of Technology Enhancements and Emerging Engineering Research, vol/issue: 2(8), pp. 32-34.

\section{BIOGRAPHIES OF AUTHORS}

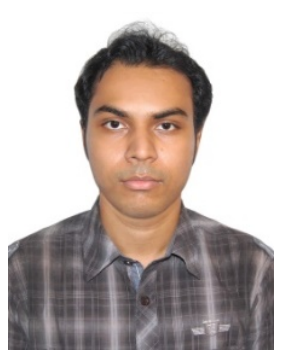

Mehdi Hasan Chowdhury received his B.Sc. (Engineering) degree in Electrical and Electronic Engineering from the Department of Electrical and Electronic Engineering (EEE), Chittagong university of Engineering and Technology (CUET), Chittagong, Bangladesh in 2013. He is currently pursuing his M.Sc. (Engineering) degree in the same field at the same University. Since 2013, he has been with the Department of EEE, CUET, Bangladesh as a Lecturer. His research interests include Embedded Systems, VLSI Technology, Wireless Communications and Biomedical Engineering.

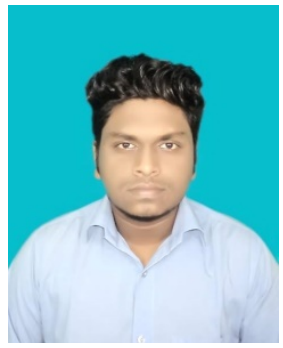

Md. Mamunoor Islam is currently pursuing his B.Sc (Engineering) degree in Electrical and Electronic Engineering from the Department of Electrical and Electronic Engineering (EEE), Chittagong university of Engineering and Technology (CUET), Chittagong, Bangladesh since 2013. His fields of interest in research include Wireless Networks, Telecommunication Engineering, Embedded Systems and Robotics. 